\title{
USO E APLICAÇÃO DA METODOLOGIA PSICOFÍSICA NA PESQUISA EM ENFERMAGEM
}

\author{
Fátima Aparecida Emm Faleiros Sousa * \\ José Aparecido da Silva
}

SOUSA, F.A.E.F.; SILVA, J.A. da. Uso e aplicação da metodologia psicofísica na pesquisa em enfermagem. Rev. latino-am. enfermagem, Ribeirão Preto, v. 4, n, 2, p. 147-78, julho 1996

Conceitos e fenômenos subjetivos, tais como atitudes sociais, opiniões e processos de julgamentos têm sido difíceis de serem mensurados acuradamente. Muitos conceitos ou variáveis em Enfermagem são de natureza subjetiva. Como nas ciências sociais, a profissão de enfermagem enfrenta muitos problemas para obter medidas precisas de tais variáveis. A metodologia psicofísica, especialmente os procedimentos de estimação de magnitude e de emparelhamento intermodal, desenvolvidos na psicofísica sensorial e sendo atualmente usados nas ciências sociais, tem se mostrado promissora em Enfermagem como um instrumento para escalonar fenômenos subjetivos. O propósito deste trabalho é descrever essas técnicas de mensuração, o paradigma teórico sobre o qual elas são baseadas e também vários estudos de âmbito social, clínico e de enfermagem, nos quais foram utilizadas essas estratégias de mensuração,

UNITERMOS: escalas em enfermagem, pesquisa em enfermagem, psicofísica e enfermagem, mensuração em enfermagem

Nesta revisão de literatura abordamos o uso e a aplicação da metodologia psicofísica na pesquisa em Enfermagem. Descrevemos como procedimentos rigorosamente desenvolvidos e popularizados no domínio da Psicofísica Sensorial

\footnotetext{
* A preparação do manuscrito foi subvencionada pelo CNPq (Processo na 30.0567-85). Correspondência pode ser enviada a Dra Fátima Faleiros, Escola de Enfermagem, Campus de Ribeirão Preto da Universidade de São Paulo, 14040-902, Ribeirão Preto-SP, Brasil. Agradecimentos são devidos aos revisores por inúmeras e profundas sugestões e comentários feitos na primeira versão do manuscrito.
}

Rev. Latino Am. Enf. - Ribeirão Preto - v. 4 - n. 2 - p. 147-178 - julho 1996 
para escalonar variáveis métricas, tais como som, brilho, distância, duração, temperatura, dentre outras, podem ser utilizados para escalonar variáveis tais como o stress e/ou reajustamentos sociais, o grau de severidade de enfermidades, a sensação subjetiva da dispnéia, o status e o poder do enfermeiro, o grau de intrusão territorial percebido pelo paciente hospitalizado, a complexidade e o controle de tarefas do enfermeiro, as expectativas sobre a qualidade dos cuidados de enfermagem, os benefícios e as barreiras na adoção de atividades recomendadas para a redução do risco cardíaco, etc. Para talos métodos de estimação de magnitude numérica e o de emparelhamento intermodal têm sido freqüentemente utilizados para estabelecer a utilidade e a validade das escalas de razão de tais variáveis sociais e clínicas (métricas e não-métricas). Este novo enfoque tem sido denominado de Psicofísica Social e Clínica. Baseado neste, podemos estabelecer o quanto (quantitativamente) um atributo é maior que um outro e não somente afirmar que eles são apenas diferentes.

A revisão de literatura foi dividida em três partes. A primeira, com o objetivo de mostrar a transição e a adaptação da metodologia psicofísica aplicada no domínio sensorial para o social, abordamos a função de potência ou Lei de Stevens e os métodos psicofísicos de estimação de magnitude e de emparelhamento intermodal. $\mathrm{Na}$ segunda, mostramos como esta metodologia pode ser adaptada para mensurar atributos não métricos (sociais e clínicos) e revisamos os experimentos nos quais ela tem sido usada com sucesso. E na última, mostramos como esta metodologia psicofísica pode ser utilizada em enfermagem, discutimos suas vantagens e também revisamos os poucos experimentos, nos quais ela foi utilizada para quantificar atributos e conceitos subjetivos no domínio da enfermagem.

\section{ACERCA DA FUNÇÃO DE POTÊNCIA (LEI DE STEVENS)}

No domínio da Psicofísica, um ramo experimental da Psicologia que lida com a mensuração e a análise dos mecanismos e/ou processos subjacentes às diferentes respostas sensoriais e/ou perceptivas, é bem conhecido que a relação entre as estimativas numéricas $(R)$ e os valores das intensidades físicas dos estímulos (E) é descrita por uma função de potência. Esta função em sua forma mais simples pode ser escrita como:

$$
R=k \cdot E^{n}(1)
$$

sendo k uma constante arbitrária que depende da unidade de medida empregada e $n$ é o expoente da função. O expoente é o parâmetro mais importante, uma vez que determina a curva que representa a relação entre o estímulo e a resposta. Se o 
expoente é exatamente igual a 1,0, a função segue uma linha reta. Neste caso, a magnitude da sensação registrada (resposta) varia linearmente com a intensidade ir do estímulo. Quando o expoente é maior do que 1,0, a curva que representa esta função é monotonicamente crescente. Se o expoente é menor do que 1,0, a curva é monotonicamente decrescente. Na Figura 1, estas três curvas estão representadas em coordenadas logarítmicas. (STEVENS, 1975; BAIRD \& NOMA, 1978).

FIGURA 1. MAGNITUDES SUBJETIVAS EM FUNÇÃO DAS MAGNITUDES FÍSICAS DOS ESTÍMULOS EM COORDENADAS LINEARES. A CURVA É POSITIVA OU NEGATIVAMENTE ACELERADA, DEPENDENDO DE SE O EXPOENTE É MAIOR OU MENOR QUE 1,0. QUANDO O EXPOENTE É IGUAL A 1,0, A FUNÇÃO DE POTÊNCIA É UMA LINHA RETA EM COORDENADAS LINEARES. AS UNIDADES DAS ESCALAS TÊM SIDO ESCOLHIDAS ARBITRARIAMENTE PARA MOSTRAR A FORMA RELATIVA DAS CURVAS (STEVENS, 1975, p. 16)

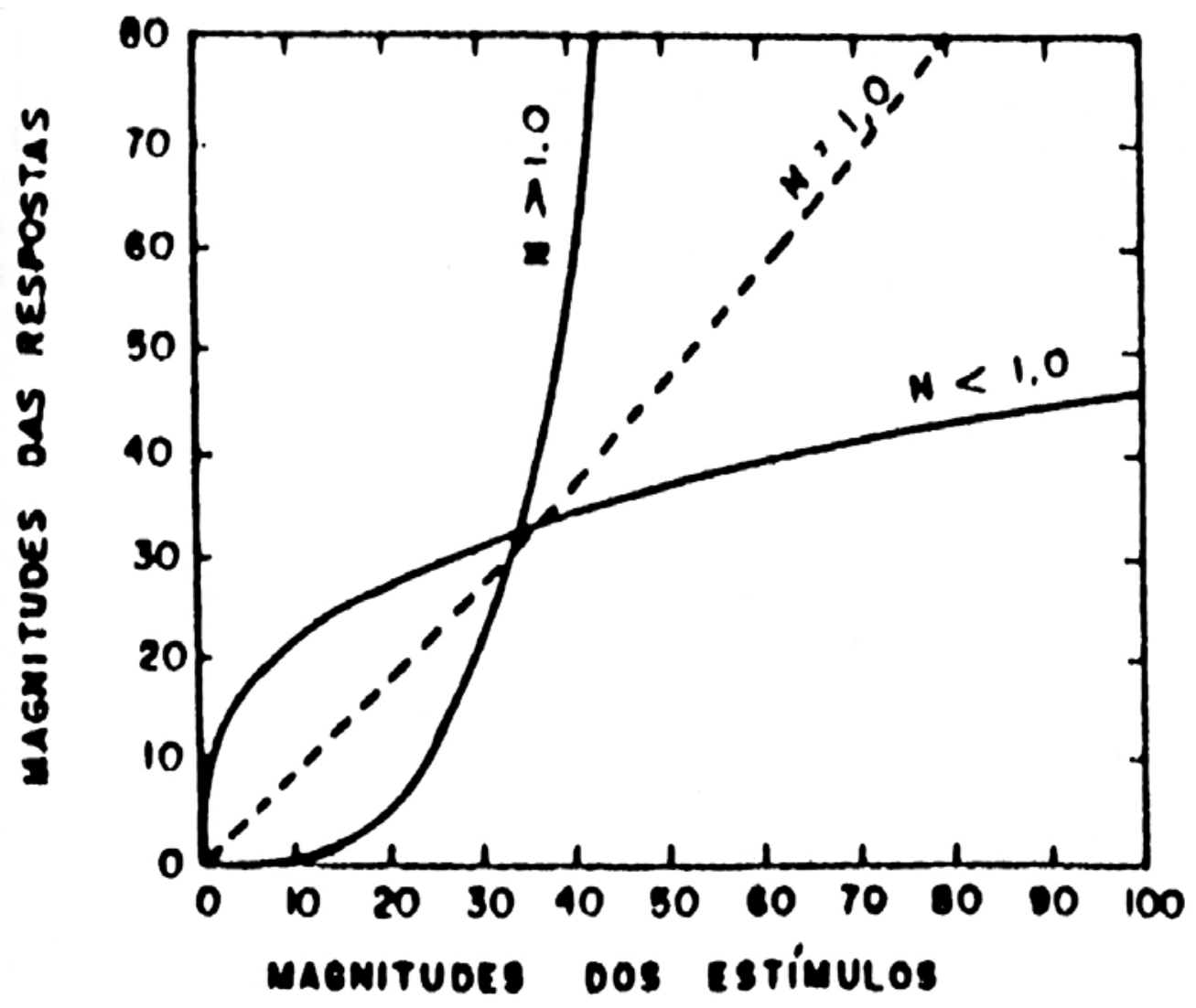


Colocando-se ambos os termos da Equação I em logaritmos, é obtida uma função linear que facilita determinar os parâmetros da função de potência bem como o coeficiente de determinação da função, o qual representa o grau de ajustamento dos dados obtidos. Então,

$$
\log R=\log k+n \log E(2)
$$

$\mathrm{Na}$ Equação 2, o expoente $\mathrm{n}$ toma-se a inclinação da função linear, enquanto o logaritmo da constante escalar k, toma-se a intersecção com o eixo das respostas.

Quanto a curva é projetada em coordenadas log-log a relação é representada por uma linha reta, independente do expoente ter um valor maior ou menor que 1,0. Este artifício matemático de projetar em coordenadas logarítmicas faz com que as curvas desapareçam e, por conseqüência, o valor do expoente é refletido diretamente na inclinação da reta. Esta relação está representada na Figura 2.

FIGURA 2. MAGNITUDES SUBJETIVAS EM FUNÇÃO DAS MAGNITUDES FÍSICAS DOS ESTÍMULOS EM COORDENADAS LOGARÍTMICAS. AS CURVAS DA FIGURA I TORNAM-SE LINHAS RETAS EM COORDENADAS LOGARÍTMICAS. A INCLINAÇÃO DA LINHA CORRESPONDE AO EXPOENTE DA FUNÇÃO DE POTÊNCIA CARACTERÍSTICO DE CADA MODALIDADE OU ATRIBUTO SENSORIAL. (STEVENS, 1975, p.17)

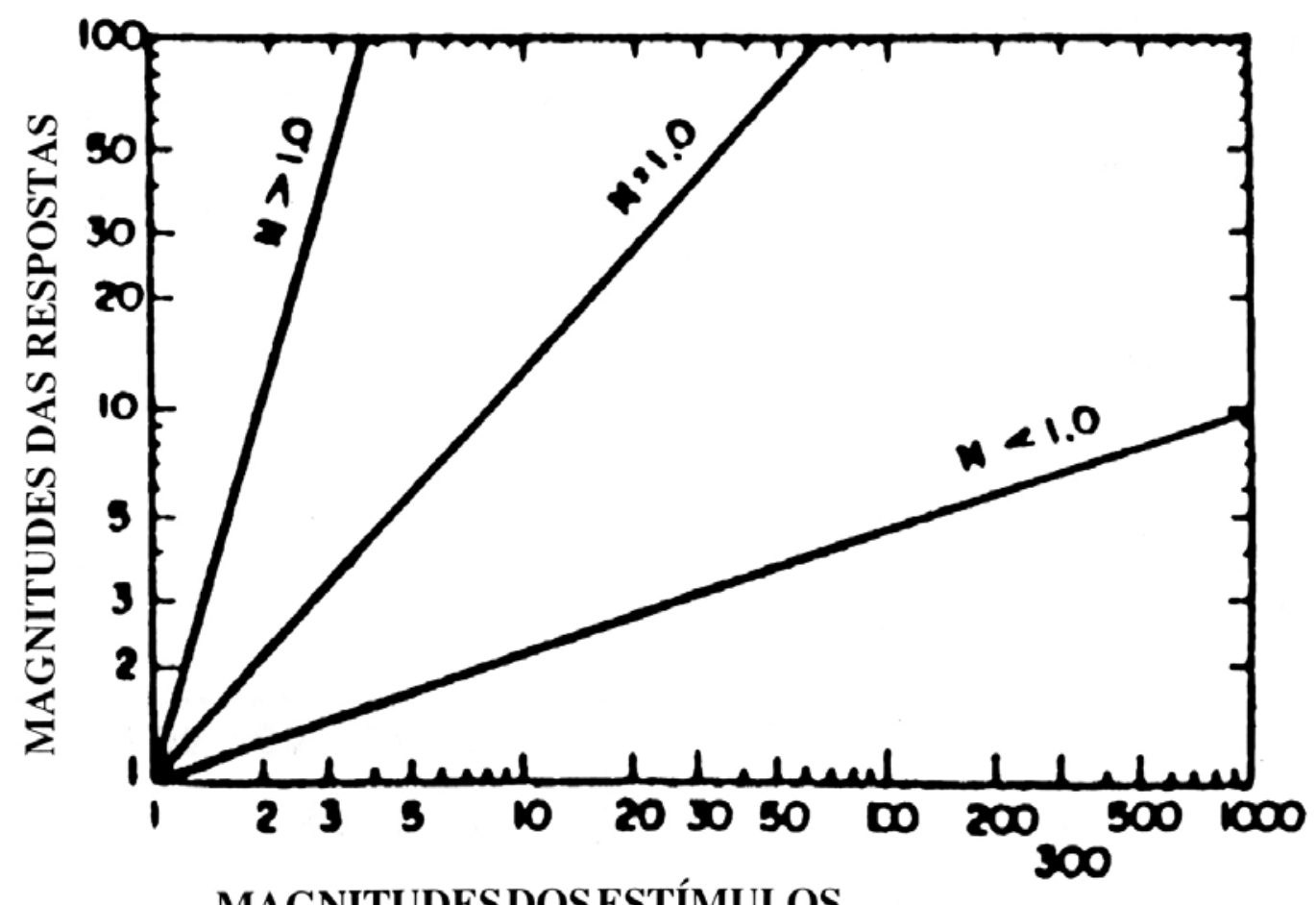


A Equação 1 é conhecida como Lei de Potência ou Lei de Stevens, e tem sido verificada para uma grande variedade de dimensões aditivas, tais como: sonoridade, brilhância, peso, comprimento, área, volume e distância visual e nos últimos anos tem sido estendida para quantificar atributos sociais ou clínicos que por natureza são estímulos não-métricos. Além disso, ela tem sido examinada sob, muitas e diferentes condições de estímulos e com ampla variedade de métodos (ver, por exemplo, DA SILVA \& MACEDO, 1982; ENGELMANN, 1966; GESCHEIDER, 1988; KRUEGER, 1989; STEVENS, 1975).

Diferentes métodos psicofísicos podem ser utilizados para calcular os parâmetros da função de potência (ver, por exemplo, DA SILVA \& MACEDO, 1982; FUKUSIMA, RIBEIRO \& DA SILVA, 1988). Todavia, a validade das escalas sensoriais e/ou perceptivas geradas a partir do método de estimação de magnitude tem sido questionada por vários pesquisadores devido à confiabilidade no uso de números para expressar as respostas sensoriais (WARREN \& WARREN, 1963; POULTON, 1968; KRUEGER, 1989).

\section{O método de estimação de magnitude}

O método de estimação de magnitude tem sido freqüentemente usado para escalonar diferentes modalidades perceptivas devido a sua rapidez de aplicação e fácil compreensão por observadores adultos e mesmo por crianças que já têm adquirido o conceito de razão entre objetos ou dimensões. Neste método, o observador recebe previamente instruções e atribui números a uma seqüência de estímulos (métricos ou não métricos) apresentados individualmente, para que faça um julgamento da magnitude percebida de cada um, de forma que esses números reflitam sua impressão subjetiva dos estímulos.

Segundo STEVENS (1971), o método de estimação de magnitude denominado por ele de emparelhamento numérico, é também uma forma de emparelhamento intermodal (ver descrição a seguir), sendo que os números são equiparados aos estímulos. Dois são os tipos de estimação de magnitude: com a presença do módulo e com módulo livre. No primeiro tipo, um estímulo é apresentado pelo experimentador como estímulo padrão e a ele é designado um valor numérico denominado módulo ou valor de referência. Em seguida, o observador deve assinalar aos estímulos subseqüentes números que sejam proporcionais ao atribuído a esse módulo, os quais representarão a razão julgada entre os diferentes estímulos apresentados pelo experimentador. Dessa forma, se um estímulo da série apresentada é considerado como tendo o dobro da intensidade daquele que recebeu o módulo, ele deve receber um valor numérico que seja duas vezes aquele atribuído ao estímulo padrão (módulo). No segundo tipo, o "método de estimação de magnitude não tem um estímulo padrão estabelecido previamente, ou seja, o módulo é livre e o observador poderá assinalar qualquer número ao 
primeiro estímulo apresentado, devendo os números assinalados para a série de estímulos refletirem razões (ou proporções) entre os estímulos julgados.

Em síntese, independente dessas duas variantes do método de estimação de magnitude, representadas pela presença ou ausência do módulo, a razão entre os números assinalados deve refletir a razão entre as intensidades percebidas dos estímulos julgados.

\section{Princípios do emparelhamento intermodal}

O emparelhamento intermodal é considerado o método mais elegante criado por Stevens e colaboradores (STEVENS, 1959; STEVENS, J .C. et al.,

1960) para validar a Lei de Potência e as escalas de magnitude. Sabemos que toda forma de mensuração é um exercício de emparelhamento. O homem primitivo contava o número de cabeças de gado do seu rebanho emparelhando-o com pedras. Uma distância é normalmente medida através do emparelhamento com os múltiplos de uma unidade de medida (no caso, comprimento), seja ela arbitrária ou padronizada, e assim por diante. Emparelha-se a intensidade da sensação com uma unidade qualquer. Assim, submetido a um estímulo o observador sente a sua intensidade e emparelha-a com aquilo que Ihe é mais familiar: o contínuo de número. Esse procedimento possibilita a construção de uma escala de sensação cuja relação com a escala de estímulo pode ser representada por uma Lei Psicofísica, no caso a Lei de Potência ou Lei de Stevens.

Podemos resumir o problema do emparelhamento intermodal na seguinte questão: É possível emparelhar, um ao outro, dois contínuos sensoriais diferentes e independentes, em lugar de emparelhar cada um deles separadamente ao contínuo de números? Para responder a esta questão, Stevens construiu, em 1958, um equipamento que permitia, ao mesmo tempo, estimular independentemente duas diferentes modalidades. Ao observador cabia manipular o controlador de um dos estímulos de modo que a sensação provocada por este parecesse ter magnitude igual à causada por outro. Em outras palavras, este equipamento proporcionava um teste de transitividade da escala sensorial em que,

$$
\text { se } A=B \text { e } A=C \text {, então } B=C
$$

Em notação fundamental, se $E_{f}$ e $E_{s}$ são dois contínuos emparelhados a $R$, o teste tradicional de transitividade pode ser ilustrado para a Lei de Stevens, como se segue:

$$
R_{f}=f\left(E_{f}\right) \text { e } R_{s}=g\left(E_{s}\right)
$$

então:

$$
f\left(E_{f}\right)=g\left(E_{s}\right)
$$


Usando esta propriedade de transitividade podemos ilustrá-la tomando dois contínuos sensoriais facilmente manipuláveis. Por exemplo, suponha que um observador faça estimativas de magnitudes de duas modalidades sensoriais e/ou perceptivas diferentes; sejam elas, força dinamométrica e som e, em seguida, funções de potência são ajustadas do modo usual. Desta forma:

$$
R_{f}=E^{a} \text { e } R_{s}=E^{b}
$$

onde (f) e (s) são, respectivamente, as notações para força dinamométrica e som, e (a) e (b) são os expoentes característicos destas duas modalidades (o fato de k ter I sido omitido a partir da Equação 1 não afeta o argumento acima). Então, quanto $R_{f}$ e $R_{s}$ são emparelhados em vários níveis de intensidade a equação resultante será:

$$
E^{a}=E^{b}
$$

em seguida, colocando ambos os termos em logaritmos podemos reescrevê-la como:

$$
a \log E_{f}=b \log E_{s} \text { ou } \log E_{f}=(b / a) \log E_{s}
$$

Os expoentes (a) e (b) são empiricamente determinados por procedimentos separados usando o método de estimação de magnitude numérica. Quanto os valores de Es e Ef são plotados em coordenadas log-log a expressão acima representa uma linha reta, ou seja, uma função de potência com a inclinação igual à razão (b/a) dos expoentes originais obtidos através do método de estimação de magnitude. Como os expoentes podem se calculados a partir de dados obtidos de experimentos, esta relação é plenamente testável e pode ser feita em ambas as direções, como no exemplo de som emparelhado à força dinamométrica e vice-versa, para corrigir o efeito de regressão, ou seja, a tendência que os observadores têm de comprimir a variável que está sob seu controle. Quando o expoente obtido aproxima-se daquele predito pela propriedade de transitividade anteriormente descrita, a escala obtida é validada. De fato, STEVENS (1975) mostra que a diferença entre ambos dada em decilog é na maioria das vezes menor que $5 \%$.

\section{O PARADIGMA DO EMPARELHAMENTO INTERMODAL APLICADO AOS ATRIBUTOS SOCIAIS E CLÍNICOS}

A questão que agora pode surgir é como este paradigma pode ser aplicado na mensuração de estímulos não métricos, tais como os atributos sociais e os 
clínicos? Vamos ilustrar hipoteticamente através da seguinte simulação: suponha que observadores sejam instruídos a emparelharem duas modalidades sensoriais quaisquer (por exemplo, força dinamométrica e comprimento de linha) a diferentes atributos sociais não métricos. Isto feito deve-se plotar os diferentes valores emparelhados (aos atributos não métricos) destas duas dimensões físicas, os de um (força dinamométrica) em função dos do outro (comprimento de linha) e imediatamente estimar os parâmetros da função de função de potência originada da reta de regressão. Estes valores podem ser comparados com aqueles obtidos por STEVENS (1975), envolvendo o emparelhamento entre as duas modalidades puramente sensoriais com dimensões físicas mensuráveis ou com aqueles obtidos da reta de regressão dos próprios observadores ou de uma amostra similar, derivados de uma tarefa denominada de calibração.

Em outras palavras, para medir a intensidade de um estímulo social, cada sujeito deve ser instruído a apertar um dinamômetro calibrado, de modo que sua impressão de força dinamométrica seja igual a sua força de impressão do estímulo social; ou seja, quanto mais forte a impressão do estímulo social tanto mais forte deve ser a força dinamométrica. Similarmente, usando-se intensidade do som como modalidade de resposta, o observador deve variar a intensidade do som através de um potenciômetro de um par de fones de ouvido, de forma que a intensidade percebida seja emparelhada com a impressão do estímulo social, de tal modo que quanto mais forte a impressão do estímulo social tanto maior deve ser a intensidade do som (LODGE, 1982).

Tal como ocorre com estímulos métricos, quando duas ou mais modalidades de respostas de magnitude são emparelhadas a um mesmo conjunto de estímulos sociais, o princípio subjacente a esse relacionamento é o de que intensidades iguais a uma mesma intensidade são iguais uma à outra. Assim, uma escala de magnitude subjetiva é validada pelo método de emparelhamento intermodal quando a inclinação obtida dos emparelhamentos com um conjunto comum de estímulos sociais se aproxima da inclinação obtida a partir da razão entre as duas inclinações características das duas medidas de respostas psicofísicas (CROSS, 1974). Devemos ressaltar que a razão predita (teste de critério para validar a escala de magnitude) é uma função entre os dois contínuos (ou modalidades) de respostas e não entre dois estímulos, uma vez que os sujeitos estão usando as duas respostas para expressar suas impressões das intensidades dos estímulos. No escalonamento social, uma primeira alternativa seria a de comparar o expoente empírico (inclinação derivada), quando as modalidades de respostas são emparelhadas com estímulos sociais, com o expoente teórico (inclinação teórica) característico dos relacionamentos dessas modalidades quanto emparelhadas com estímulos físicos. Portanto, para ser validada a escala de atributos sociais, a razão empírica obtida quando os sujeitos fazem o emparelhamento das duas modalidades de respostas com os estímulos sociais, deve ser então a mais próxima da razão estabelecida para essas duas modalidades de respostas emparelhadas a estímulos (LODGE, 1982). 
Uma segunda alternativa seria a comparação desse expoente empírico derivado das estimativas dos estímulos sociais com o expoente empírico obtido num experimento de calibração, onde os mesmos sujeitos tenham emparelhado as mesmas duas modalidades de respostas com estímulos métricos. Esse experimento de calibração envolve uma tarefa de escalonamento psicofísico que serve como treino dos observadores no uso das duas modalidades de respostas para que façam julgamentos proporcionais. Essas mesmas duas modalidades deverão ser empregadas num segundo experimento de escalonamento de magnitude, no qual os observadores julgarão a intensidade de um dado estímulo social.

O pressuposto teórico-experimental é que os mesmos vieses que afetam as respostas aos estímulos sensoriais (métricos) atuariam de modo análogo nas respostas aos estímulos sociais (não-métricos). Qualquer que seja a alternativa de comparação, o importante é que cada um dos expoentes empíricos e a razão entre eles precisam ser funções de potência. Sendo assim, quando esse critério é satisfeito a escala derivada é uma escala de razão, dita psicofisicamente validada (BAIRD \& NOMA, 1978; STEVENS, 1975).

\section{MENSURAÇÃO DE A TRIBUTOS SOCIAIS}

Nesta secção apresentaremos sucintamente experimentos nos quais foram escalonados atributos sociais (métricos) através de rigorosos métodos psicofísicos desenvolvidos no domínio da psicofísica sensorial. O objetivo é exemplificar a riqueza da diversidade metodológica utilizada para o escalonamento de contínuos dessa natureza, bem como descrever o processo de validação psicofísica envolvido nesses escalonamentos.

\section{Importância política dos monarcas suecos}

Em estudo feito por EKMAN \& KÜNNAPAS (1963) foram utilizadas estimativas de razão e de comparação aos pares para construir escalas da importância política de 11 monarcas suecos, com os quais os observadores estavam familiarizados. Os resultados comparativos demonstraram que quando os valores estimados do escalonamento de comparação aos pares foram representados graficamente em coordenadas lineares em função dos valores estimados do escalonamento de razão, o gráfico foi curvilíneo. Posteriormente, quando os valores escalares derivados do método de comparação aos pares foram representados graficamente em função dos logaritmos das estimativas de razão, o resultado foi uma linha reta. Portanto, este padrão de resultados é similar àquele usualmente 
obtido quando ambos os procedimentos psicofísicos são empregados para escalonar dimensões métricas. Tais resultados mostram que o contínuo não métrico da importância política dos monarcas suecos é um contínuo quantitativo e não qualitativo.

\section{Valores estéticos de desenhos e de manuscritos}

Dois estudos sobre os valores estéticos de manuscritos foram realizados por EKMAN \& KONNAPAS (1960, 1962a). Em ambos, amostras de manuscritos foram escalonadas pelo método que comparação aos pares e de estimação de razão.

Tomados juntos os dados mostraram que também para este tipo de contínuo, tal como ocorre com alguns contínuos métricos, a amplitude dos estímulos é um fator importante em determinar a relação funcional entre os valores escalares derivados de métodos diferentes. Embora tenham mostrado que uma relação logarítmica descreve muito bem a relação entre os valores escalares derivados do método de comparação aos pares e os valores escalares derivados do método de estimação de razão, a forma da função é freqüentemente mascarada quando a amplitude é pequena.

Num estudo relacionado, EKMAN \& KONNAPAS (1962b) empregaram os métodos de estimação de categorias, de razão e de comparação aos pares para escalonar desenhos de diferentes árvores. Os resultados novamente mostraram que os valores escalares originados dos métodos de estimação de categorias e de comparação aos pares são logaritmicamente relacionados aos valores escalares derivados do método de estimação de razão. Todavia, os valores escalares obtidos nos dois primeiros métodos são linearmente relacionados entre si. Portanto, também para este contínuo a mesma relação usualmente encontrada com dimensões métricas é fortemente estabelecida.

Preferências musicais Julgamentos estéticos na esfera musical foram investigados por KOHN (1965), o qual utilizou os métodos de estimação de magnitudes e de estimação de categorias. Diferentes grupos de sujeitos julgaram seleções vocais e peças de piano. Os resultados mostraram que em coordenadas mono-log, as correlações produto-momento entre os valores escalares das estimativas de magnitude variaram de 0,90 a 0,96. Embora tenha havido uma concavidade ascendente que usualmente ocorre quando as escalas de categorias são projetadas em função dos logaritmos das escalas de magnitude, a grande variabilidade dos valores impediu que a mesma fosse mais saliente. Os dados também mostraram que esta relação entre as escalas de categorias e escalas de magnitudes foi invariante a despeito de diferenças na idade, sexo, educação, ocupação e patologia dos sujeitos. Devido a isso, KOHN 
(1965) destacou que essas invariâncias empíricas sugerem a utilidade e a robustez do método de estimação de magnitude em revelar processos de julgamentos complexos.

\section{Preferências por relógios de pulso}

INDOW (1961) apresentou figuras e descrições de vários relógios de pulso para estudantes universitários japoneses e solicitou-lhes que fizessem julgamentos pelo método de comparação aos pares e estimativas de razão. $\mathrm{Na}$ realidade, os estudantes emparelharam o comprimento de uma linha ao valor subjetivo de sua preferência, ou seja, realizaram um tipo de emparelhamento intermodal. Comparando os valores escalares obtidos por meio do comprimento de linha com os valores escalares derivados do método de comparação aos pares, Indow demonstrou uma relação aproximadamente logarítmica entre os dois tipos de valores escalares.

Numa outra parte do experimento, INDOW (1961) solicitou aos estudantes para indicar, em yens, qual seria o preço justo para cada um dos relógios de pulso. Os resultados mostraram que a relação entre as estimativas médias dos preços e os valores escalares de preferência em coordenadas log-log segue uma função de potência com um expoente igual a 0,32. Este valor indica, portanto, que a relação entre o preço estimado e a preferência não é linear.

\section{Julgamento moral}

EKMAN (1962) usou os métodos de comparação aos pares e o de estimação de razão para escalonar diferentes atitudes descritas verbalmente, representando comportamentos mais ou menos imorais ou criminosos. Os resultados, semelhantes àqueles obtidos em outros estudos, mostraram uma relação logarítmica entre os valores escalares derivados dos julgamentos obtidos pelo método de comparação aos pares e os dos julgamentos derivados das estimativas de razões. Portanto, o contínuo de julgamento moral também pode ser considerado como quantitativo, se considerarmos como critério a obtenção de uma função logarítmica entre os dados dos diferentes métodos (mensuração de diferenças e de razões).

\section{Comportamento racista}

DAWSON \& BRINKER (1971) fizeram um estudo em que solicitaram aos sujeitos que julgassem o quão racista eram sentenças que expressam diferentes comportamentos de uma pessoa branca em relação à negra. A tarefa dos sujeitos 
consistia em indicar sua opinião de quão racista era o comportamento descrito através do método de emparelhamento intermodal envolvendo as modalidades de som e força dinamométrica. Para analisar os resultados os valores dos emparelhamentos de som foram colocados em função dos valores dos emparelhamentos de força dinamométricas, em coordenadas logarítmicas. Tais dados mostraram claramente uma função de potência com um expoente igual a 0,39 , indicando que a pressão sonora é uma função de potência da força dinamométrica. Este valor obtido experimentalmente é muito próximo daquele de 0,38 , que é o valor esperado a partir da razão entre os valores de 0,64 (expoente para som) e 1,70 (expoente para força dinamométrica). Portanto, estes resultados sugerem que os sujeitos podem indicar os graus de suas opiniões emparelhando-as a duas intensidades sensoriais diferentes. Eles também são consistentes com aqueles obtidos quando emparelhamentos envolvendo estas duas modalidades foram feitos diretamente, uma com a outra (ver também STEVENS, 1966).

\section{Grau de liberalismo-conservadorismo}

O julgamento do grau de liberalismo-conservadorismo expresso em diferentes afirmações é um contínuo cuja relação entre as estimativas de categorias (ou de comparação aos pares) e estimativas de razões não segue uma função aproximadamente logarítmica. Este contínuo foi investigado por EKMAN \& KÜNNAPAS (1963), os quais realizaram dois experimentos envolvendo diferentes números de afirmações. Os dados de ambos os experimentos mostraram que a relação entre os valores escalares obtidos pelo método de estimação de razões é claramente linear em função dos valores escalares obtidos pelo método de comparação aos pares. Uma interpretação da diferença entre estes resultados com aqueles obtidos com outros contínuos, proposta por Ekman e Künnapas, é que o grau de conservadorismo representa uma posição sobre um contínuo qualitativo que se estende de um liberalismo típico a um conservadorismo típico, enquanto os contínuos anteriores representam a quantidade de beleza, imoral idade e influência política. Portanto, nesse sentido o contínuo de conservadorismo pode ser qualitativo e os contínuos de valores estéticos, julgamento moral e prestígio político podem ser considerados quantitativos, se focalizarmos a relação funcional entre as estimativas de diferenças (estimativas de categorias ou comparação aos pares) e as estimativas de razões (estimativas de magnitudes).

\section{Percepção do poder nacional}

Um estudo dos mais interessantes envolvendo escalonamento social foi realizado por SHINN (1969). Ele quantificou as opiniões a respeito do poder 
nacional de várias nações. Cada nação foi descrita em termos de três atributos: população, produto nacional bruto e porcentagem do PNB destinado à militarização. Os resultados mostraram que todos os três atributos contribuíram para o poder nacional aparente, mas o crescimento do poder nacional cresceu de modo diferente para quantidades crescentes de cada um dos três atributos. Foi de mostrado que os dados podem ser descritos muito bem por três funções de potência, uma diferente da outra. Shinn também verificou como as três variáveis de poder nacional se combinavam para criar o poder nacional total percebido. Para isso foram testados dois modelos, o aditivo e o multiplicativo. O modelo multiplicativo provou ser superior, indicando que a percepção do poder nacional pode ser regida por uma equação multiplicando os três atributos e na qual o poder cresce mais rapidamente quando a produtividade aumenta.

\section{Utilidade subjetiva de bens e de benefícios públicos}

KEMP $(1988,1991)$ empregou o método de estimação de magnitude para investigar a utilidade subjetiva de bens e de benefícios públicos pessoal e nacionalmente consumidos. As medianas das estimativas de magnitudes foram calculadas para cada um dos itens pessoais e nacionais e, em seguida, foram projetadas em função dos custos reais avaliados de cada item. Os expoentes das funções de potência variaram entre 0,13 e 0,46. Além disso, os dados mostraram que os bens pessoais são mais relacionados aos seus respectivos custos do que os benefícios públicos. Os dados também sugerem que a relação utilidade-custo para benefícios públicos não é a mesma que aquela para bens pessoais. A primeira foi percebida como sendo de utilidade mais alta e a função de potência foi caracterizada por um expoente menor para esses benefícios públicos.

\section{Opiniões sócio-políticas}

LODGE e colaboradores (LODGE et al., 1982; LODGE, 1982; LODGE et al., 1975; LODGE et al., 1976) realizaram vários experimentos em que investigaram quais atributos as pessoas associam com partidos políticos, candidatos, instituições e polícia, e também quão intensamente as pessoas concebem sobre estes atributos. Por exemplo, quão intensamente uma pessoa se identifica com um partido político? Quanto de confidência uma pessoa tem da Suprema Corte? Quão comprometidas são as pessoas com os processos democráticos?

Para responder a estas questões foi composta uma escala com 30 adjetivos variando desde absolutamente perfeito até desgostoso, os quais constituíram os itens usados para mensurar o suporte político. Diferentes grupos de sujeitos usaram as modalidades de respostas de estimação numérica de forças dinamométricas 
e de pressões sonoras para avaliar a quantidade de suporte inserido nestes adjetivos. As médias geométricas foram calculadas para cada uma das modalidades de respostas. As correlações entre os logaritmos destas médias foram altas, indicando um alto grau de dependência linear entre as medidas, e cada um dos expoentes empíricos aproximou-se do expoente esperado dentro dos limites de 95\% de confidência. Este padrão de resultados constitui uma alta validade de constructo e também forte evidência de um contínuo psicológico subjacente ao suporte político.

\section{Seriedade de ofensas e de crimes}

Em 1964, Sellin e Wolfgang publicaram no livro "Mensuração da Delinqüência" os resultados de três anos ininterruptos de investigações usando métodos psicofísicos para mensurar a criminal idade em geral, e a delinqüência, em particular. $O$ delineamento enfatizou eventos delinqüentes e não as pessoas delinqüentes. $O$ propósito principal foi mensurar a quantidade e o tipo de prejuízo para a comunidade gerado por um ato anti-social. Os procedimentos psicofísicos de estimação de categorias e de estimação de magnitudes foram aplicados aos eventos selecionados com o objetivo de converter a seriedade julgada destes eventos em escores numéricos. Tal como ocorreu com outros contínuos não métricos, a relação entre as estimativas de categorias e as estimativas de magnitudes do grau de delinqüência é uma função logarítmica. Quando as estimativas de categorias são projetadas em função dos logaritmos das estimativas de magnitudes a relação é aproximadamente linear, embora com uma leve concavidade ascendente. Tais relações mostram que a seriedade das ofensas é um contínuo quantitativo. Em adição, os resultados de SELLIN \& WOLFGANG (1964) revelaram que tais relações são invariantes tanto em função da idade quanto das amostras dos sujeitos. Portanto, estes resultados indicam que a própria ofensa é aparentemente o determinante principal do julgamento de sua seriedade.

\section{Preferência e prestígio ocupacionais e profissionais}

Um dos primeiros estudos que investigou através de métodos psicofísicos escalares o prestígio ocupacional e profissional foi realizado por PERLOE (1963). Ele utilizou e comparou os métodos de estimação de magnitudes e estimação de categorias para escalonarem uma lista de 100 ocupações. Os dados revelaram que a escala de categorias de prestígio ocupacional é uma função aproximadamente logarítmica da escala de estimação de magnitudes, quando os sujeitos não limitaram a amplitude de julgamento das profissões consideradas de mais alto prestígio. Portanto, estes dados indicam que o contínuo de prestígio profissional tem características quantitativas. Tais resultados foram posteriormente confirmados 
por KÜNNAPAS \& WILKSTROEM (1963), DAWSON \& BRINKER (1971), DAWSON \& MIRANDO (1976) e HARDIN \& BIRNBAUM (1990), os quais mostraram também que o expoente empírico derivado da função de potência relacionando o emparelhamento de intensidade de sons a forças dinamométricas não foi diferente daquele predito pela propriedade de transitividade do emparelhamento intermodal. Tomados em conjunto, os dados destes experimentos mostraram que o contínuo de prestígio e de preferências ocupacionais e profissionais possui características quantitativas e que entre estudantes americanos e suecos, a profissão de médico é a que possui o mais alto prestígio ou é a profissão mais preferida.

\section{Status Social}

Diferente dos estudos anteriores nos quais inúmeras ocupações foram mensuradas em termos de seus respectivos prestígios, preferências e desejabilidade, HAMBLIN e colaboradores (HAMBLIN \& SMITH, 1966; HAMBLIN, 1971) investigaram o status local e o profissional de professores universitários. O status local do professor foi avaliado em seu próprio departamento de trabalho, enquanto o status profissional foi avaliado considerando-se a profissão e a disciplina ministrada em relação a similares em outras partes do país. Os resultados mostraram que o status local é uma função de potência multivariada das seguintes variáveis: mérito de ensinar e da liderança do professor. Somente estas duas variáveis explicam $97 \%$ da variância dos julgamentos do status local do professor. De outro lado, o status profissional foi uma função de potência multivariada de 4 variáveis independentes: mérito de publicação e mérito de ensinar como as mais relevantes, e cordialidade (negativamente relacionada) e tempo de serviço como as menos relevantes, as quais explicam 99\% da variância dos julgamentos do status profissional do professor.

\section{MENSURAÇÃO DE ATRIBUTOS CLÍNICOS}

Nesta secção apresentaremos alguns experimentos nos quais foram escalonados atributos fisiológicos e patológicos através dos procedimentos psicofísicos desenvolvidos no domínio da Psicofísica Sensorial. Importante mencionar que estes atributos podem ter ou não dimensões físicas mensuráveis. Por exemplo, de um lado, na determinação da acuidade os estímulos são intensidades de sons mensuráveis fisicamente. De outro lado, na mensuração do stress e/ou reajustamentos sociais, os estímulos são diferentes eventos de vida que não podem ser mensurados fisicamente. O objetivo desta secção é mostrar que o conhecimento 
metodológico e teórico obtido e desenvolvido no domínio da Psicofísica Sensorial pode ser aplicado em diagnóstico clínico e também na avaliação de fatores, estímulos ou eventos de vida que são estressantes.

\section{Stress elou reajustamentos sociais}

HOLMES e colaboradores (RAHE, SMITH, KJAER \& HOLMES, 1964; MASUDA \& HOLMES, 1967; HOLMES \& RAHE, 1967; RUCH \& HOLMES, 1971) elaboraram uma escala contendo 43 itens de eventos de vida que requeriam diferentes graus de reajustamentos. Alguns desses itens foram: casamento, morte da esposa, gravidez, mudança de residência, dificuldades sexuais, divórcio, problemas no emprego e férias. Esta escala foi denominada por HOLMES \& RAHE (1967) de escala de magnitude de reajustamentos sociais. A tarefa dos sujeitos consistiu em dar uma estimativa de magnitude para cada um dos itens dessa escala que refletisse o grau relativo de reajustamento necessário para se acomodar a este evento, independente da desejabilidade do mesmo. O evento de vida, casamento, foi tomado como estímulo padrão e a ele foi designado o valor de 500. Os outros eventos deveriam ser estimados proporcionalmente ao casamento tomado como padrão. Os resultados foram extremamente consistentes e invariantes entre diferentes culturas e subculturas de amostras de sujeitos. Posteriormente, a escala foi amplamente utilizada em diferentes contextos, como o hospitalar (VOLICER \& BOHANNON, 1975) e com diferentes faixas etárias, como na velhice (MUHLENKAMP et al., 1975).

Dois estudos realizados por Holmes ilustram claramente a metodologia psicofísica empregada e permitem afirmar que o contínuo de stress e/ou reajustamento social é um contínuo com características qualitativas ou na linguagem de Stevens, metatético. No primeiro estudo, MASUDA \& HOLMES (1967) solicitaram aos sujeitos para darem estimativas de magnitudes numéricas aos diferentes eventos de vida, tomando como padrão o evento casamento. Os resultados mostraram um coeficiente de concordância muito alto entre as três medidas de tendência central utilizadas: média geométrica, média aritmética e mediana, e também uma relação linear entre o erro padrão e a média geométrica das estimativas de cada item. No segundo estudo, RUCH \& HOMES (1971) compararam as estimativas de magnitudes com as estimativas de comparações aos pares de 11 itens ou eventos de vida previamente selecionados. Comparação entre os métodos revelou, de um lado, que os valores escalares resultantes das estimativas de magnitudes são altamente correlacionados com os valores escalares derivados das estimativas de comparações aos pares. O coeficiente de correlação de ordem foi bastante elevado. De outro lado, a relação entre as medlas geométricas das estimativas de magnitudes e os valores escalares ajustados resultantes das comparações aos pares foi linear, indicando, portanto, que o contínuo de stress e/ou reajustamento social possui apenas características qualitativas. Posteriormente, 
BIRNBAUM \& SOTOODEH (1991) e BIRNBAUM (1992; ver também CRANDALL, 1992) analisando a mensuração do stress sob o ponto de vista da teoria geral da mensuração, confirmaram que este contínuo é qualitativo e não quantitativo.

\section{Gravidade de enfermidades}

O método de estimação de magnitudes também foi utilizado com sucesso na mensuração da gravidade de diferentes enfermidades. De fato, WYLER et al. (1968) elaboraram uma lista contendo 126 enfermidades a qual foi enviada pelo correio a duas amostras distintas: uma não médica e a outra médica. A tarefa dos sujeitos consistia em estimar a magnitude da gravidade das enfermidades assinalando a cada uma delas um número que fosse proporcional ao valor de 500 designado à enfermidade da úlcera péptica. Exemplos de algumas enfermidades foram: constipação intestinal, enxaqueca, diarréia, sinusite, acne, astigmatismo, menopausa, menstruação, eczema, alergia medicamentosa, gonorréia, coma, depressão, epilepsia, derrame cerebral, ataque cardíaco, uremia, câncer e leucemia. As duas amostras foram altamente concordantes em suas estimativas de magnitudes de cada uma dessas enfermidades bem como em suas respectivas ordenações. Os resultados também indicaram que as variáveis idade, sexo, estado civil, etc., afetam numa extensão maior os julgamentos feitos pela amostra não médica do que aqueles feitos pela amostra médica. Combinando as estimativas de magnitudes de ambas as amostras, estas indicaram que a caspa foi a enfermidade com menor estimativa de magnitude, o aborto foi uma enfermidade com estimativa de magnitude mediana e a leucemia foi a enfermidade com maior estimativa de magnitude. O mesmo padrão de resultados foi obtido por WYLER et al (1971) e por VOLICER \& BOHANNON (1975).

Em outro estudo similar, WYLER et al. (1970) replicaram o trabalho original usando uma outra amostra de médicos e analisando as estimativas em função de suas respectivas especialidades médicas. Os resultados mostraram que as estimativas de magnitudes numéricas feitas por médicos de diferentes especialidades não foram significativamente diferentes entre si, exceto apenas para 5 enfermidades, indicando, portanto, que a variável especialidade do respondente não é significativa.

\section{Deficiência de fala e de pronúncia}

DAWSON \& BRINKER (1971) investigaram pelo método de emparelhamento intermodal (som, força dinamométrica e duração temporal) a facilidade de pronunciar diferentes trigramas. Os resultados mostraram que o expoente obtido foi muito similar ao esperado derivado da razão entre os expoentes 
usualmente obtidos com estimativas de magnitude de som e com força dinamométrica. Também uma alta correlação de ordem indicou que os sujeitos são consistentes em seus emparelhamentos feitos por meio de dois contínuos físicos diferentes. Em outro estudo similar, DAWSON \& MIRANDO (1973) verificaram que estas estimativas são estáveis e repetíveis e que a relação entre as estimativas de categorias e as estimativas de emparelhamentos de forças dinamométricas é uma função negativamente acelerada. Em adição, foi observado que a relação entre as estimativas da facilidade e as estimativas da dificuldade de pronunciar diferentes trigramas é uma função de potência com um expoente igual - 1,0.

O julgamento do sotaque explícito na pronúncia de uma frase foi investigado por BRENNAN et al. (1975) usando entonações diferentes de uma só frase obtidas de diferentes estudantes bilíngües (inglês-espanhol). Os resultados mostraram que os expoentes obtidos experimentalmente a partir da função de potência ajustada entre as estimativas de magnitudes e os emparelhamentos de forças dinamométricas, em coordenadas logarítmicas, foram muito próximos do valor esperado a partir da razão entre os expoentes usualmente encontrados para julgamentos de números e para julgamentos de forças dinamométricas.

Mais recentemente, Fucci e colaboradores (FUCCI et al., 1990; ELLIS \& FUCCI, 1991) utilizaram o método de estimação de magnitudes para investigar a estabilidade das escalas obtidas dos julgamentos de clareza e inteligibilidade da fala feitos por fonoaudiólogos e sujeitos inexperientes. Os resultados não indicaram diferenças significativas nas respostas para sentenças sem sentido e com sentido e, além disso, um alto coeficiente de fidedignidade teste-reteste foi obtido entre duas tentativas obtidas numa mesma sessão. Frente a este padrão de resultados, os autores discutem a importância, a potencialidade e as aplicações do procedimento de estimação de magnitudes em pesquisas clínicas e sociais.

\section{Deficiências auditivas}

A aplicação de procedimentos psicofísicos a problemas clínicos tem sido extremamente valiosa por fornecer métodos para sistematizar e localizar funções anômalas e para determinar a eficácia de um tratamento. De fato, os métodos psicofísicos tem sido centrais para a análise audiométrica da perda auditiva, para o desenvolvimento de próteses auditivas e para os esforços em usar a visão e o tato como substitutos da audição. Vamos exemplificar como um procedimento psicofísico pode ser utilizado no diagnóstico de deficiências auditivas em pacientes com perda neural e condutiva. De uma amostra de pacientes de uma clínica, THALMAN (1965) selecionou um grupo de 10 pacientes, os quais tinham audição normal em um dos ouvidos e uma grande perda auditiva, aproximadamente igual a $50 \mathrm{~dB}$., no outro ouvido. Cinco pacientes tinham perda condutiva e cinco tinham perda neural. $O$ experimento requeria que os pacientes ajustassem a amplitude de uma vibração aplicada ao dedo indicador para emparelhá-lo à intensidade aparente de um som de $1.000 \mathrm{~Hz}$ aplicado a um ou ao outro ouvido do paciente. As médias 
geométricas dos emparelhamentos foram calculadas e projetadas uma em função da outra. As relações obtidas foram funções de potências, com uma função característica para cada tipo de deficiência auditiva.

Ao analisar estes resultados, STEVENS (1975) concluiu que mesmo embora um órgão sensorial possa ser deficiente, um experimento psicofísico bem delineado e conduzido empregando emparelhamentos intermodais pode ser também útil em revelar a natureza da deficiência. Além disso, os métodos psicofísicos tais como estimação de magnitudes e emparelhamento intermodal são muito mais fáceis de serem aplicados do que as tarefas psicoacústicas freqüentemente utilizadas em clínicas otológicas. Eles requerem menos explicações, preparos e treinos. Devido, talvez, a estas facilidades de uso, alguns pesquisadores têm empregado métodos psicofísicos com pacientes surdos com o propósito de explorar sua utilidade na seleção de aparelhos de correção auditiva. Por exemplo, GELLER \& MARGOLIS (1984) e KNIGHT \& MARGOLIS (1984) compararam os procedimentos otológicos clássicos de mensuração indireta dos níveis de conforto e desconforto da sonoridade, com o procedimento psicofísico direto de estimação de magnitudes. A grosso modo, os resultados mostraram a vulnerabilidade dos procedimentos otológicos clássicos em função de mudanças nas instruções, procedimento psicométrico e tipo de amplitude de estímulos, indicando que estas medidas podem não ser úteis na seleção de aparelhos auditivos. Esta instabilidade pode ser causada devido às diferentes interpretações de conforto dentre e entre pacientes e clínicos. Ao contrário, os métodos escalares diretos produzem medidas estáveis e repetíveis mesmo entre sujeitos inexperientes e produzem resultados similares entre grupos de sujeitos muito diferentes. Além disso, uma outra aplicação dos métodos psicofísicos é a determinação da sonoridade da fala exprienciada por sujeitos normais. Com esta informação, uma estratégia diferente pode ser atingida na seleção de aparelhos auditivos. Isto é, ao invés de determinar os níveis de saída de sons que caem dentro de uma amplitude confortável, torna-se possível determinar a resposta de ganho de freqüência e características de compressão que restauram a sonoridade normal da fala para pessoas surdas (SCHIAVETTI et al., 1981). Estes autores mostraram através da comparação entre os métodos de estimação de magnitudes e de estimação de categorias tanto para pessoas com audição normal, quanto para pessoas com surdez congênita que, a inteligibilidade da fala é um contínuo quantitativo. Isto porque para ambos os grupos de sujeitos, a relação entre as estimativas de categorias e as estimativas de magnitudes foi curvilínea em coordenadas lineares.

\section{Dispnéia}

A dispnéia definida como a percepção desconfortável e desagradável de dificuldade de respirar, é um fenômeno clínico complexo difícil de ser mensurado. 
De fato, a dispnéia inclui tanto a percepção de dificuldade de respirar quanto a reação a esta percepção. A dispnéia tem tanto componentes afetivos e cognitivos quanto componentes neurosensoriais e mecânicos. Esses componentes coletivamente contribuem para a percepção da capacidade respiratória (MAHLER et al.,1987; HARVER, 1987; HARVER et al., 1986; HARVER \& KOTSES, 1987; DA SILVA \& FUKUSIMA, 1989). Cada uma dessas percepções faz parte do constructo de dispnéia em sua totalidade. Não obstante, escalas clínicas têm sido freqüentemente utilizadas para avaliar esta desagradável sensação e recentemente algumas delas têm sido comparadas com métodos psicofísicos diretos tais como estimação de magnitudes tanto com amplitude limitada quanto com amplitude ilimitada (NIELD et al., 1989; NIELD \& KIM, 1991).

KILLIAN et al. (1981) usaram a força de resistência externa e a resistência elástica para respiração para determinar se o expoente da função de potência poderia ser confiavelmente estimado. A tarefa dos sujeitos consistiu em designar uma estimativa de magnitude para cada uma das forças de resistência externa e elástica. Os dados revelaram expoentes diferentes para a força de resistência externa e para a capacidade respiratória. Todavia, a correlação produto-momento entre os expoentes individuais obtidos das duas variáveis foi alto, sugerindo que tanto o volume quanto o fluxo de entrada de ar contribuem para a percepção respiratória que ocorre em conexão com a capacidade respiratória. Também, GOTTFRIED et al. (1985) exploraram a percepção tanto da força de resistência, externa quanto da resistência elástica para a respiração em sujeitos com doença pulmonar obstrutiva crônica e em sujeitos normais, para determinar qual diferença na percepção da capacidade respiratória ocorre quando a magnitude da capacidade é expressa em termos do nível e duração da força muscular respiratória. Os resultados indicando que não houve diferenças entre os dois grupos na percepção de volume inspirado e na força respiratória muscular sugerem que o volume e a força não explicam a redução no expoente. Ao contrário, diferenças em integrar e processar estímulos aferentes no sistema nervoso central foram as explicações mais prováveis (NIELD et al., 1989).

Com estimativas de magnitudes de amplitude limitada, BURDON et al. (1982) usaram uma modificação da escala de categoria-razão (estimativas de magnitudes limitadas) (BORG, 1982; BORG \& OTTOLSON, 1986) para estabelecer a relação entre a intensidade do esforço respiratório e o grau de obstrução do fluxo aéreo como mensurado pelo volume respiratório forçado em 1 segundo. Os dados obtidos confirmaram que a percepção da intensidade do esforço respiratório aumentou enquanto o volume expiratório diminuiu. Outros estudos têm empregado a escala de categoria-razão como um contínuo de resposta, para quantificar a percepção de intensidade da dispnéia. Em geral, as relações obtidas suportam a teoria que afirma que a percepção da capacidade respiratória é a percepção do esforço muscular respiratório, porque cada variável dependente poderia ser um indicador válido do esforço respiratório (LE BLANC et al., 1986). Também, o 
método de estimação de magnitudes tem sido empregado para estudar a relação entre fadiga muscular e dispnéia. Os dados mostraram, todavia, que nenhuma relação existe entre a severidade da percepção do esforço respiratório (um indicador da dispnéia) e a presença de um padrão de fadiga diafragmático.

\section{O PARADIGMA DO EMPARELHAMENTO INTERMODAL APLICADO EM ENFERMAGEM}

\section{O problema da mensuração em Enfermagem}

O desenvolvimento de uma metodologia para mensurar precisamente os cuidados de enfermagem e seus efeitos no paciente é um processo contínuo. Um dos maiores obstáculos para o progresso da pesquisa em Enfermagem e no seguimento de numerosas questões clínicas substancias é a falta de instrumento para indexar os conceitos de respostas subjetivas, tais como as percepções, opiniões, atitudes e julgamentos sobre o binômio saúde-doença, a satisfação do paciente, a dor, a fadiga, o julgamento da qualidade dos cuidados e/ou opiniões dos auxiliares de enfermagem ou enfermeiros sobre a complexidade, a importância e a qualidade dos cuidados fornecidos, dentre outros.

O método de estimação de magnitude, tal como adaptado nas ciências sociais, é uma estratégia escalar que se tem mostrado promissora para indexar precisamente as respostas subjetivas dos clientes e dos enfermeiros. Esta estratégia envolve assinalar ou designar um número para emparelhar uma resposta subjetiva individual a estímulos sociais numa série de julgamentos proporcionais. Como tal, estimação de magnitude é um tipo de procedimento escalar de magnitude que pode gerar medidas num nível de razão.

Surge novamente com a adaptação destas técnicas escalares nas ciências sociais, a questão da validade das escalas de respostas ou de sensações. Vários pesquisadores têm sugerido que, a lei psicofísica também pode ser aplicada na relação entre estímulos sociais e respostas subjetivas. Neste caso, a estratégias de estimativa numérica não é o ponto central ou crítico. O ponto central é a violação da premissa básica da função de potência, isto é, se razões iguais de estímulos produzem razões iguais de respostas (STEVENS, 1961, 1969). Embora muitos pesquisadores em ciências sociais tenham aderido a este escalonamento de razão (HAMBLIN \& SMITH, 1966; RAINWATER, 1971), fica evidente que muitos estímulos sociais, frente aos tipos de conceitos estudados, não podem atingir o critério de razão e freqüentemente são apenas escalonados ordinalmente (HINSHAW, 1983; HINSHAW \& FIELD, 1974; HINSHAW \& MURDAUGH, 1985; SELLIN \& WOLFANG, 1964; SHINN, 1969). Tais investigadores tentaram argüir que escalas de respostas de razão eram ainda produzidas a partir de várias perspectivas, como por exemplo, a existência de escalas de razões desiguais 
(HAMBLIN, 1971) e a relação entre as escalas de categorias e as de magnitudes (SHINN, 1969). Mas estas posições nem sempre têm sido sustentadas experimentalmente porque vários testes envolvendo o emparelhamento intermodal conduzidos no domínio da psicofísica foram apenas parcialmente replicados nas pesquisas em ciências sociais (CROSS, 1974; LODGE et al., 1975). Nas ciências sociais, o emparelhamento intermodal requer a obtenção de uma série de múltiplas respostas com cada diferente modalidade em relação a uma série central de estímulos (LODGE et al., 1976).

Quando a lei psicofísica é investigada e técnicas de escalonamento de razão são adaptadas numa outra ciência aplicada, por exemplo, em enfermagem e saúde pública, a questão central da validade da propriedade do escalonamento de razão da mensuração da resposta deve ser novamente testada. O valor das estratégias de mensuração repousa tanto na produção de escalas de razão quanto na explicação da relação entre as respostas subjetivas e os estímulos sociais. Assim, foi necessário replicar os estudos iniciais com o emparelhamento intermodal para estímulos sociais classificados ordinalmente e testar a existência de nível de razão das escalas de respostas subjetivas quanto indexando fenômenos em Enfermagem.

\section{A adaptação do paradigma na Enfermagem}

A adaptação do paradigma de Stevens aplicado a estímulos e/ou atributos sociais e clínicos tem sido usada por alguns pesquisadores em Enfermagem numa tentativa de estabelecer índices de respostas subjetivas de enfermeiros, de atendentes de enfermagem e de clientes e/ou pacientes hospitalares. Todavia, HINSHAW (1983) salientou um problema básico no uso do método de estimação de magnitude, bem como de outros contínuos ou modalidades de respostas. Segundo ela, nos estudos de Enfermagem uma premissa básica da função de potência é violada; isto é, os atributos sociais e/ou clínicos raramente são escalonados num nível de razão e usualmente são classificados ordinalmente. Sob essa condição, em Enfermagem também surge novamente a questão: são as escalas de respostas subjetivas produzidas num nível de razão? Tal como nas ciências sociais, o uso do método de emparelhamento intermodal para testar a validade das escalas de razão com conceitos derivados da Enfermagem requer uma adaptação do método psicofísico básico. Na adaptação proposta por LODGE (1982), o modelo requer que duas ou mais modalidades ou contínuos de respostas sejam usados para obter estimativas subjetivas de um simples, mas comum arranjo de estímulos. Esquematicamente, o modelo pode ser representado como:

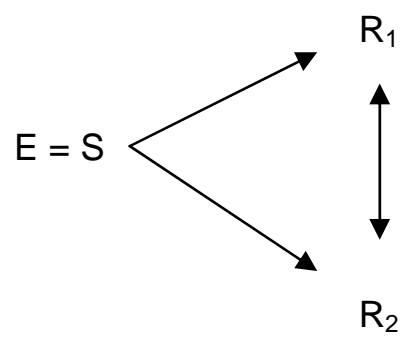


onde o estímulo (E) resulta numa impressão subjetiva individual (5) mensurada através de duas modalidades de respostas quantitativas diferentes (R 1 e R2) (LODGE, 1982). Os valores das respostas das estimativas subjetivas são dadas pelas expressões (ignorando as constantes):

$$
\mathrm{R}_{1}=\mathrm{E}_{1} \text { e } \mathrm{R}_{2}=\mathrm{E}_{2} \quad \text { (LODGE et al., 1974) }
$$

Para proceder com a comparação das estimativas dos estímulos, as modalidades de respostas devem ser emparelhadas (STEVENS, 1960, 1968). De fato, isto é possível porque cada uma das modalidades de resposta psicofísica produz uma estimativa acurada da intensidade do estímulo (Hamblin, 1971a; STEVENS et al., 1960, 1966, 1971; STEVENS \& GALANTER, 1957). Assim, se $R_{1}$ $=R_{2}$, então a relação de $E_{1}$ e $E_{2}$ torna-se $E_{1}^{n}=E_{2}^{m}$ que quando expressa em coordenadas logarítmicas torna-se:

$$
\log E_{1}=(m / n) \log E_{2} \quad \text { (LODGE et al., 1974) }
$$

Quando esta função de sensação igual é plotada em coordenadas log-log a função é uma linha reta com a inclinação igual a $\mathrm{m} / \mathrm{n}$. Se há um alto grau de validade convergente, a inclinação da projeção $(\mathrm{m} / \mathrm{n})$ é igual a razão dos expoentes característicos das duas modalidades de respostas $\left(\begin{array}{llll}R_{1} & \text { e } & R_{2}\end{array}\right)$ (GESCHEIDER, 1976; STEVENS et al., 1960, 1969). Decorrente da validade desse procedimento aceitam-se as propriedades de razão das mensurações e, portanto, confirma-se a lei de potência (DAWSON \& BRINKER, 1971; STEVENS et al., 1960,1968, 1971; STEVENS \& GALANTER, 1957).

\section{Mensuração de atributos em Enfermagem}

Os métodos de mensuração (estimação de magnitudes, estimação de categorias e emparelhamento intermodal) e a lei psicofísica (lei de potência ou lei de Stevens) que descrevemos e ilustramos nas várias secções anteriores, têm sido usados por alguns poucos pesquisadores em Enfermagem com o propósito de determinar um índice de respostas ou de conceitos subjetivos dos enfermeiros e de pacientes hospitalizados ou não. Nos últimos 15 anos estes pesquisadores descobriram a robustez e o rigor da metodologia psicofísica para determinar medidas em nível de razão de conceitos subjetivos tais como: controle, dor, ansiedade, intrusão no espaço territorial subjetivo do paciente hospitalizado e opiniões pessoais acerca de restrições para os cuidados de saúde e de higiene e acerca da identificação, da definição e da valorização dos indicadores de qualidade dos cuidados de enfermagem recebidos (ATWOOD \& HINSHAW, 1977; FIELD \& HINSHAW , 1977; HINSHAW \& FIELD, 1974; HINSHAW \& OAKES, 1977; 
HINSHAW \& SCHEPP. 1983; SENNOTT-MILLER, 1987; SCHEPP, 1991). Também, HINSHAW \& FIELD (1974) tentaram determinar um índice das opiniões das enfermeiras sobre os fatores que influenciam os seus julgamentos do status profissional de colegas.

\section{Vantagens da metodologia psicofísica aplicada em Enfermagem}

Em diferentes revisões da literatura, Hinshaw e seus colaboradores (HINSHAW, 1983; SENNOTT-MILLER \& MILLER, 1987; MEEK et al., 1992) têm divulgado e discutido a riqueza, as vantagens e as desvantagens do uso e aplicação da metodologia psicofísica em Enfermagem, seja ela uma ciência ou prática social. Por exemplo, SENNOTT-MILLER \& MILLER (1987) e MEEK et al. (1992) mostraram que a estratégia psicofísica é superior às inúmeras outras estratégias comumente utilizadas em Enfermagem por fornecer informações quantitativas sobre a intensidade dos julgamentos dos pacientes, médicos e enfermeiras.

As seguintes características da metodologia psicofísica demonstram sua superioridade quando comparada com outros métodos comumente utilizados para escalonar variáveis psicossociais, tais como as escalas de Guttman, Likert, Thurstone e Diferencial Semântico: (1) os sujeitos selecionam livremente as medidas de respostas, (2) o número de participantes pode ser pequeno, (3) escalas de mensuração em nível de razão são geradas, e, como conseqüência, aumenta a sensibilidade e o rigor da mensuração, pois nesta todas as operações estatísticas e aritméticas são admissíveis, ( 4) os julgamentos e as escalas produzidas são consistentes e estáveis com coeficientes de fidedignidade (produto-momento) teste-reteste variando de 0,90 a 1,00, (5) os procedimentos de estimação de magnitudes e emparelhamento intermodal são fáceis de serem entendidos e usados pelos pacientes, auxiliares de enfermagem, enfermeiras e médicos, (6) os procedi mentos são de baixo custo e não há perda de dados e os mesmos podem ser coletados individual ou coletivamente e, (7) os procedimentos são encarados pelos sujeitos como "jogo", por isso reduzem a fadiga e a monotonia comumente encontradas em outras estratégias. Em resumo, estas vantagens da metodologia psicofísica podem ser enriquecidas pela qualidade dos dados obtidos e a atitude positiva dos participantes.

Para ilustrar estas vantagens podemos mencionar o estudo de SCHEPP (1991) que comparou o método de estimação de magnitudes com a escala de Likert nos esforços de mães em manipularem suas energias físicas e emocionais para lidarem com suas crianças hospitalizadas. Os resultados mostraram que as respostas de razão derivadas do método de estimação de magnitude foram substancialmente diferentes daquelas obtidas com a Escala de Likert quanto às intensidades dos estímulos, portanto, sugerindo que estimação de magnitudes é superior em detectar variações com níveis de estímulos elevados, uma vez que com este método a amplitude de respostas é ilimitada. SENNOTT-MILLER \& MILLER (1987) registraram que os resultados obtidos através de estimação de magnitude 
produzem freqüentemente altos coeficientes de fidedignidade (produto-momento) testereteste, isto é, ao redor de 0,91.

\section{Estimação de magnitude da complexidade e da autonomia das atividades do cuidar em Enfermagem}

O relatório técnico-científico elaborado por HINSHAW \& MURDAUGH (1985) utilizando a metodologia psicofísica para validar escalas de razão de conceitos em Enfermagem, merece ser considerado com mais detalhes. $O$ relatório ilustra com clareza e exemplifica como esta metodologia pode ser aplicada e ser útil em Enfermagem. É o único trabalho em que o emparelhamento intermodal foi genuinamente empregado para escalonar variáveis do campo da Enfermagem e, também, no qual se mostra a viabilidade e a conveniência dos procedimentos psicofísicos para a mensuração direta das atitudes ou opiniões envolvidas nas atividades do cuidar em Enfermagem. Em outras palavras, o trabalho mostra como o enfoque psicofísico centrado no estímulo muda para o enfoque centrado na pessoa ou como se medem diretamente reações psicosociais.

As autoras selecionaram previamente 13 tarefas que representavam cinco atividades que são freqüentes, quatro moderadas e quatro infrequentes realizadas pelas enfermeiras. Estas treze tarefas variaram em termos de complexidade e controle. Exemplos destas tarefas foram: verificar os sinais vitais, administrar medicamentos, checar se os drenos e sondas funcionam corretamente, ensinar os pacientes a assimilar os tratamentos diários e manipular medicamentos orais, ajudar o paciente e a família a lidarem com a morte eminente e orientar (dar apoio emocional) a pacientes que têm comportamentos hostis, nervosos e confusos. Os sujeitos foram requisitados a julgarem estas tarefas sob dois conceitos: complexidade da tarefa e controle da tarefa. A complexidade da tarefa foi definida como quão difícil é manipular a atividade de Enfermagem considerando tanto as técnicas quanto os princípios técnicos-científicos envolvidos. A autonomia ou controle da tarefa foi definido como a quantidade de autonomia que um profissional tem sobre suas responsabilidade e atividades de trabalho.

Essencialmente dois métodos foram empregados: a escala de Likert e o método de emparelhamento intermodal. Com a escala de Likert os sujeitos foram instruídos a assinalar uma alternativa variando de 1 a 7 , com o escore 1 indicando uma atividade extremamente sem complexidade e o escore 7 indicando uma atividade extremamente complexa. Com o método de emparelhamento intermodal os sujeitos foram instruídos a produzir quatro tipos diferentes de respostas: estimação de magnitudes, emparelhamento de comprimentos de linhas, emparelhamento de forças dinamométricas e emparelhamento de pressões sonoras. Uma tarefa padrão com seu respectivo módulo foi previamente determinada para cada sujeito. Os conceitos de complexidade e de controle das tarefas foram escalonados apenas pelo método de estimação de magnitudes, enquanto o conceito 
de complexidade foi escalonado também pelos emparelhamentos de comprimentos de linhas, forças dinamométricas e pressões sonoras.

Para os julgamentos baseados na escala de Likert foram calculadas as médias aritméticas e para os emparelhamentos, as médias geométricas de cada modalidade para cada uma das 13 tarefas, separadamente para cada um dos conceitos. Os expoentes das funções de potência ajustadas combinando-se as diferentes modalidades de emparelhamentos não diferiram em mais do que $6 \%$ dos expoentes preditos pela transitividade das escalas, com coeficientes de determinação variando de 0,88 a 1,00. Quando as escalas de Likert comparadas com as escalas de estimação de magnitudes e com a derivada dos emparelhamentos de comprimentos de linhas em coordenadas lineares, as relações entre elas foram lineares. De outro lado, quando as escalas de Likert foram comparadas com as escalas derivadas dos emparelhamentos de forças dinamométricas e pressões sonoras em coordenadas lineares, as relações entre elas resultaram em funções quase-logarítmicas. Portanto, as primeiras relações que o contínuo não métrico representado pelas diferentes tarefas de atividades das Enfermeiras é qualitativo, enquanto as segundas relações sustentam que o contínuo possui características quantitativas. Todavia, quando calculamos, a partir dos dados publicados por HINSHAW \& MURDAUGH (1985), a Lei de Ekman, isto é, a relação entre as estimativas de magnitudes ou de categorias derivadas da escala de Likert com suas respectivas variabilidades dadas pelo erro padrão da média, verificamos claramente que no primeiro método a relação é linear enquanto que no segundo a relação é na forma de "u" invertido. Portanto, apenas com o primeiro os dados seguem a Lei de Ekman. Assim, dentro da teoria psicofísica este contínuo pode ser considerado como quantitativo ou protético. Os resultados também mostraram qual as correlações produto-momento entre os valores escalares dos conceitos, complexidade e controle das tarefas foram altas e negativas, tanto para as estimativas de magnitude quanto para a escala de Likert, indicando que os dois conceitos, complexidade e controle, são negativamente relacionados. Considerados juntos, os dados relatados por HINSHAW \& MURDAUGH (1985) suportam que os procedimentos de estimação de magnitudes e de emparelhamento intermodal fornecem escalas de conceitos em Enfermagem em nível de mensuração de razão. As escalas de razão destes conceitos são estáveis, válidas e fidedignas.

Em resumo, podemos claramente observar que as características essenciais e listadas anteriormente acerca da metodologia psicofísica são inalteradas quando esta é adaptada e operacionalizada para mensurar fenômenos e/ou conceitos subjetivos em Enfermagem. Portanto, acreditamos ter demonstrado através desta revisão da literatura na qual diferentes variáveis psicossociais (não métricas) foram estimadas por meio de métodos psicofísicos derivando escalas num nível de mensuração de razão, que a Enfermagem, tanto como ciência ou quanto prática social, tem adquirido uma opção de mensuração adicional para escalonar seus conceitos ou fenômenos subjetivos com a vantagem de produzir escalas em nível 
de mensuração no qual todas as operações estatísticas e aritméticas são permissíveis, gerando assim índices mais sensitivos e válidos.

\section{USE AND APPLICATION OF PSYCHOPHYSICAL METHODOLOGY IN NURSING RESEARCH}

Concepts and subjective phenomena such as social attitudes, opinions and judgment processes have always been difficult to measure accurately. Many concepts or variables in nursing are of a subjective nature. As with the social sciences, the nursing profession has faced many problems in attempting to obtain precise measurements of such variables. The psychophysical methodology, specially the magnitude estimation and cross-modality matching procedures developed in sensory psychophysics and currently being used in the social sciences shows promise for providing nursing with an instrument of precisely scaling subjective phenomena. The purpose of this paper is to describe these measurement techniques, the theoretical paradigm on which it is based, and several social, clinical and nursing studies that have utilized these sensitive measurement strategies.

UNITERMS: nursing scaling, research in nursing, psychophysics and nursing, nursing methodology, nursing measurement

\section{USO Y APLICACIÓN DE LA METODOLOGÍA PSICOFÍSICA EN LA INVESTIGACIÓN EN ENFERMERÍA}

Conceptos y fenómenos subjetivos, con las actitudes sociales, opiniones $y$ actos de juzgamiento han sido difíciles de ser medidos adecuadamente. Muchos conceptos o variables en la enfermería son de naturaleza subjetiva. De forma similar a las ciencias sociales, a profesión de enfermería tiene muchos problemas para la obtención de medidas precisas de tales variables. Los métodos psicofísicos, especialmente los procedimientos de estimación de la magnitud y modalidades cruzadas, desarrollados en la psicofísica de los sentidos sensoriales y que en la actualidad están siendo utilizados en las ciencias sociales, se han mostrado bastante útiles en la enfermería como un instrumento para cuantificar fenómenos subjetivos. El objetivo de este trabajo es detallar estas técnicas de medidas; el fundamento teórico en que se basan y también varios estudios de carácter social, clínico y de enfermería, donde fueron utilizados estos métodos de cuantificación.

TÉRMINOS CLAVES: escalas en enfermería, investigación en enfermería, psicofísica y enfermería, cuantificación en enfermería 


\section{REFERÊNCIAS BIBLIOGRÁFICAS}

01. ATWOOD, J .R. ; HINSHAW , A. S. Multiple indicators of nurse patient outcomes as a method for evaluating a change in staffing patterns. Communicating Nursing Research, v. 10, p. 235-255, 1977.

02. BAIRD, J.C.; NOMA, E. Fundamentals of scaling and psychophysics. New York: Wiley, 1978.

03. BIRNBAUM, M. H. Predicting healthy from stress: Response to Crandall. Psychological Science, v. 5, p. 319-320, 1992.

04. BIRNBAUM, M. H.; SOTOODEH, Y. Measurement of streen: Scaling the magnitude of life changes. Psychological Science, v. 4, p. 236-242, 1991.

05. BORG, G. Psychophysical bases of perceived exertion. Medicine and Science in Sports and Exercise, v. 14, p. 377-381, 1982.

06. BORG, G.; OTTONSON, D. The perception of exertion in physical work. MacMillan: London, 1986.

07. BRENAN, E. M; RYAN, E. B.; DAWSON, W. E. Scaling of apparent accentedness by magnitude estimation and sensory modality matching. Journal of Psychological Research, v. 4, p. 27-36,1975.

08. BURDON, J. G. W; JUNIPER, E. F; KILLIAN, K. J.; HARGREAVE, F. E.; CAMPBELL, E. J. M. The perception of breathlessness in asthma. American Review of Respiratory Disease, v. 126, p. 858-828, 1982.

09. CRANDALL, C. S. Psychophysical scaling of stressful life events. Psychological Science, v. 3, p. 256-258, 1992.

10. CROSS, D. V. Some technical notes on psychophysical scaling. In: Moskowitz, B. Scharf; Stevens, J.C. (Eds.). Sensation and measurement in honor of S.S.Stevens: The Netherlands: Reidel, 1974. p. 23-36.

11. DA SILVA, J. A..; FUKUSIMA, S. S. Constancy of individual exponents for inspired lung volume: a comment on Harver. Perceptual and Motor Skills, v. 68, p. 193$194,1989$.

12. DA SILVA, J. A.; MACEDO, L. A função-potência na percepção: significado e procedimento de cálculo do expoente. Arquivos Brasileiros de Psicologia, v. 34, p. 27-45, 1982.

13. DAWSON, W. E.; BRINKER, R.P. Validation of ratio scales of opinion by multimodality matching. Perception \& Psychophysics, v. 9, p. 413-417, $1971 .$.

14. DAWSON, W. E.; MIRANDO, M.A. Sensory-modality scale for pronounce ability of trigrams and its relation to free-recall learning. Perceptual and Motor Skills, v. 36, p. 1219-1224, 1973.

15. EKMAN, G. Measurement of moral judgments: A comparison of scaling methods. Perceptual and Motor Skills, v. 15, p. 3-9, 1962.

16. EKMAN, G.; KÜNNAPAS, T. Note on direct and indirect scaling methods. Psychological Report, v. 6, p. 174, 1960. 
17. EKMAN, G.; KÜNNAPAS, T. Scales of aesthetic value. Perceptual and Motor Skills, v. 14, p. 19-26, 1962a.

18. EKMAN, G.; KÜNNAPAS, T. Measurement of aesthetic value by direct and indirect methods. Scandinavian Journal of Psychology, v. 3, p. 3-12, 1962b.

19. EKMAN, G.; KÜNNAPAS, T. A further study of direct and indirect scaling methods. Scandinavian Journal of Psychology, v. 4, p. 77-80, 1963.

20. ELLIS, L. W.; FUCCI, D. J. Magnitude estimation scaling of speech intelligibility: effects of listeners' experience and semantic-syntactic context. Perceptual and Motor Skills, v. 73, p. 295-305, 1991.

21. ENGELMAN, A. A lei de potência de Stevens: Um caso de constância perceptiva? Jornal Brasileiro de Psicologia, v. 3, p. 19-48, 1966.

22. FIELD, M.A.; HINSHAW, A.S. Magnitude estimation: a method for measurement subjective phenomena. Communicating Nursing Research, v. 9, p.1-18, 1977.

23. FUCCI, D. J; ELLIS, L. W.; PETROSINO, L. Speech clarity intelligibility. Perceptual and Motor Skills, v. 18, p. 2-14, 1990.

24. FUKUSIMA, S. S.; RIBEIRO, G.; DA SILVA, J.A. Cálculo da função de potência de Stevens para microcomputadores. Psicologia: Teoria e Pesquisa, v. 4, p. 96101, 1988.

25. GELLER, D.; MARGOLIS, R. H. Magnitude estimation of loudness: Application to hearing aid selection. Journal of Speech and Hearing Research, v. 27, p.2027, 1984.

26. GESCHEIDER, G. A. Psychophysics: method and theory. Hillsdale: LEA, 1976.

27. Psychophysical scaling. Annual Review of Psychology, v. 39, p. $169-200,1988$.

28. GOTTFRIED, S. B; REDLINE, S.; ALTOSE, M.D. Respiratory sensation in chronic obstructive pulmonary disease. American Review of Respiratory Disease, v. 132, p. 954-959, 1985.

29. HAMBLIN, R. H. Mathematical experimentation and sociological theory: a critical analysis. Sociometry, v. 34, p. 423-452, 1971.

30. HAMBLIN, R.L.; SMITH, C.R. Values, status and professors. Sociometry, v. 29, p. 183-196,1966.

31. HARDIN, C.; BIRNBAUM, M. C. Malleability of ratio judgments of occupational prestige. American Journal of Psychology, v. 103, p. 1-20, 1990.

32. HARVER, A. Constancy of individual exponents for category production of inspired lung volume. Perceptual and Motor Skills, v. 65, p. 779-785, 1987.

33. HARVER, A.; KOTSES, H. Perception of static respiratory forces in young and old subjects. Perception \& Psychophysics, v. 41, p. 449-454, 1987. 
34. HARVER, A; TENNEY, S. M.; BAIRD, J.C. A cautionary note on the interpretation of the power law for respiratory effort. American Journal of Respiratory Disease, v. 133, p. 341-342, 1986.

35. HINSHAW , A.S. Magnitude estimation: An instrument strategy. Communicating Nursing Research, v. 16, p. 75- 77, 1983.

36. HINSHAW , A. S.; FIELD, M. A. An investigation of variables that underlie collegial evaluation: peer review. Nursing Research, v. 23, p. 292-300, 1974.

37. HINSHAW, A. S.; OAKES, D. Theoretical model testing: patients', nurses' and physicians' expectations of quality nursing care. Communicating Nursing Research, v. 10, p. 163-189, 1977.

38. HINSHAW, A. S.; SCHEPP, K. Territorial intrusion and client outcomes: The use of magnitude estimation. Communicating Nursing Research, v. 16, p.77, 1983.

39. HINSHAW, A. S.; MURDAUGH, C. Validity of ratio measurement of nursing concepts: a cross modality study. Washington, DC: Division of Nursing, Department of Health and Human Services. 1985. (Final Report, Grant NU 00971)

40. HOLMES, T. H.; RAHE, R. H. The social readjustment rating scales. Journal of Psychosomatic Research, v. 11, p. 213-218, 1967.

41. INDOW, T. An example of motivation research applied to product design. Chosa Gijutsu, v. 102, p. 45-60, 1961.

42. KEMP, S. Magnitude estimation of non monetary items. Bulletin of the Psychonomic Society, v. 26, p. 544-547,1988.

43. . Magnitude estimation of the utility of public goods. Journal of applied Psychology, v. 76, p. 533-540, 1991.

44. KILLIAN, K. J; MAHUTTE, C. K.; CAMPBELL, J. M. Magnitude scaling of externally added loads to breathing. American Review of Respiratory Disease, v. 123, p. 12-15, 1981.

45. KNIGHT, K. K.; MARGOLIS, R. H. Magnitude estimation of loudness II: Loudness perception in presbycusic listeners. Journal of Speech and Hearing Research, v. 27, p. 28-32, 1984.

46. KOHN, S.D. Scaling musical preferences. Journal of Experimental Psychology, v. 70, p. 79-82, 1965.

47. KRUEGER, L. E. Reconciling Fechner and Stevens: toward a unified psychophysical law. Behavioral and Brain Sciences, v. 12, p. 251-320, 1989.

48. KÜNNAPAS, T.; WIKSTROEM, I. Measurement of occupational preferences: A comparison of scaling methods. Perceptual and Motor Skills, v. 17, p. 611-624, 1963.

49. LE BLANC, P; BOWIE, D. M; SUMmERS, E; JONES, N. L.; KILLIAN, K. J. Breathlessness and exercise in patients with cardiorespiratory disease. American Review of Respiratory Disease, v. 133, p. 21-25, 1986. 
50. LODGE, M. Magnitude scaling: quantitative measurement of opinions. Beverly Hills: Sage Publications, 1982.

51. LODGE, M; CROSS, D; TURSKY, B; FOLEY, M.A.; FOLEY, H. Calibration and cross-modal validation of ratio scales of political opinion in survey research. Social Science Research, v. 5, p. 325-347, 1976.

52. LODGE, M; CROSS, D; TURSKY, B.; TANENHAUS, J. The Psychophysical scaling and validation of a political support scale. American Journal of Political Science, v. 19, p. 611-649, 1975.

53. LODGE, M; CROSS, D; TURSKY, B; TANENHAUS, J.; REEDER, R. The Psychophysical scaling of political support in the real world. Political Methodology, v. 2, p. 159-182, 1976.

54. LODGE, M; CROSS, D.; TURSKY, B. The social-psychophysical scaling of political opinion. In: WEGENER B. (ed.), Social attitudes and psychophysical measurement. Hillsdale: LEA, 1982. p. 177-198.

55. MAHLER, D. A; ROSIELLO, R. A; HARVER, A; LENTINE, T; MCGOVERN, J.F.; DAUBENSPECK, J. A. Comparison of clinical dyspnea ratings and psychophysical measurements of respiratory sensation in obstructive airway disease. American Review of Respiratory Disease, v. 135, p. 1229-1233, 1987.

56. MASUDA, M.; HOLMES, T. H. Magnitude estimation of social readjustments. Journal of Psychosomatic Research, v. 11, p. 219-225, 1967.

57. MEEK, P. M; SENNOTT-MILLER, L.; FERKETICH, S. L. Scaling stimuli with magnitude estimation. Research in Nursing \& Health, v. 15, p. 77- 81, 1992.

58. MUHEENKAMP, A. F; GRESS, L. D.; FLOOD, M. A. Perception of life change events by the elderly. Nursing Research, v. 24, p. 109-113, 1975.

59. NIELD, M.; KIM, J. J. Reability of magnitude estimation for dyspnea measurement. Nursing Research, v. 40, p. 17-19, 1991.

60. NIELD, M; KIM, M. J.; PATEL, M. Use of magnitude estimation for estimating the parameters of dyspnea. Nursing Research, v. 38, p. 77-80, 1989.

61. PERLOE, S. I. The relation between category-rating and magnitude estimation judgments of occupational prestige. American Journal of Psychology , v. 76, p. 395-403, 1963.

62. RAHE, R. H: MEYER, M; SMITH, M; KJAER, G.; HOLMES, T. H. Social stress and illness onset. Journal of Psychosomatic Research, v. 8, p. 35-44, 1964.

63. RAINWATER, L. Interim report on social status, income and family behavior. Unpublished paper, Joint Center for Urban Studies on the Massachusetts: Institute of Technology and Harvard University, 1971.

64. RUCH, L. O.; HOLMES, T. H. Scaling of life change: comparison of direct and indirect methods. Journal of Psychosomatic Research, v. 15, p. 221 -227, 1971.

65. SCHEPP, K. G. Factors influencing the coping effort of mothers of hospitalized children. Nursing Research, v. 40, p. 42-46, 1991. 
66. SCHIAVETTI, N; METZ, D. E.; SILTER, R. W. Construct validity of direct magnitude estimation and interval scaling of speech intelligibility: Evidence from a study of the hearing impaired. Journal of Speech and Hearing Research, v. 24, p. 441445, 1981.

67. SELLIN, J. T.; WOLFGANG, M. E. The measurement of delinquency. New York: Wiley, 1964.

68. SENNOTT-MILLER, L.; MILLER, J. L. L. Difficulty: A neglected factor in health promotion. Nursing Research, v. 36, p. 268-272, 1987.

69. SHINN JR, A.M. An application of psychophysical scaling techniques to the measurement of national power. Journal of Politics, v. 31. p. 932-951,1969.

70. STEVENS, J. C; MACK, J. D.; STEVENS, S.S. Growth of sensation on seven continua as measured by force of hand grip. Journal of Experimental Psychology, v. 59, p. 60-67, 1960.

71. STEVENS, S.S. Cross-modality validation of subjective scales for loudness, vibration, and electric shock. Journal of Experimental Psychology, v. 57, p. 201-209, 1959.

72. . To honor fechner and repeal his law. Science, v. 133, p. 80-86, 1961.

73. A metric for the social consensus. Science, v. 151, p. 530-541, 1966.

74. On predicting exponents for cross-modality matches. Perception \& Psychophysics, v. 6, p. 251-256, 1969.

75. . (1971) Issues in psychophysical measurement. Psychological Review, v. 78, p. 426-450, 1971.

76. Psychophysics: Introduction to its perceptual, neural and social prospects. New York: Wiley, 1975.

77. STEVENS, S.S.; GALANTER, E. H. Ratio scales and category scales for a dozen perceptual continua. Journal of Experimental Psychology, v. 54, p. 377-411, 1957.

78. THALMAN, R. Cross-modality matching in the study of abnormal loudness functions. Laryngoscope, v. 75, p. 1708-1726, 1965.

79. VOLICER, B. J.; BOHANNON, M. W. A hospital stress rating scale. Nursing Research, v. 24, p. 352-364, 1975.

80. W ARREN, R. M.; WARREN, R. P. (1963). a critique of S.S. Stevens' "new psychophysics". Perceptual and Motor Skills, 16, 797-810.

81. WYLER, A. R; MASUDA, M.; HOLMES, T. H. Magnitude of life events and seriousness of illness. Psychosomatic Medicine, v. 33, p. 115-122, 1971.

82. WYLER, A. R; MASUDA, M.; HOLMES, T. H. Seriousness of Illness rating scale. Journal of Psychosomatic Research, v. 11, p. 363-374, 1968.

83. WYLER, A.R; MASUDA, M.; HOLMES, T. H. The seriousness of illness rating scale: Reproducibility. Journal of Psychosomatic Research, v. 14, p. 59-64, 1970. 